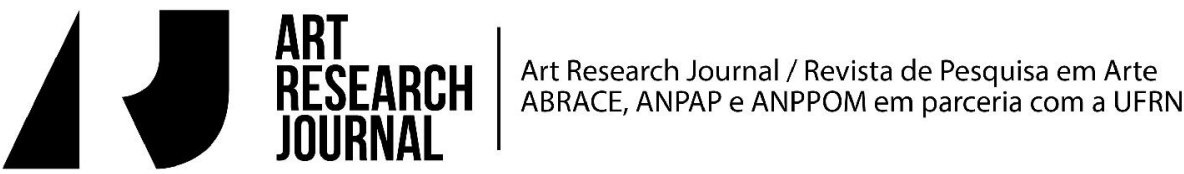

\section{O espectador avisado e a pesquisa em artes}

\author{
Maria Helena Werneck \\ PPGAC-UNIRIO/CNPq
}

Dois pequenos livros inspiradores, um de autoria do teórico e crítico de teatro, Georges Banu ${ }^{1}$, outro do historiador e filósofo da arte, George Didi Huberman², conduzem o trabalho de refletir sobre a pesquisa na pesquisa em artes, de modo a descrever as lógicas de investigação que nortearam a escrita dos dois trabalhos. A perspectiva é a de criar com eles a cumplicidade entre espectadores de um tipo especial, aquele que se dirige às artes da cena com interesse na elaboração de um estudo, em que se mobiliza uma bibliografia viva ou bibliografia interior (ambos são conceitos de Banu), ou seja, espetáculos e artistas aos quais se assistiu ao longo do tempo, mais curto ou mais extenso. Cada um dos livros tem a sua particularidade, não só no ponto de partida, com a escolha do objeto a ser analisado - um texto e suas inúmeras encenações, um dançarino de flamenco e um de seus bailados -, mas também porque praticam escritas que incorporam modos de subjetivação do discurso.

\section{Biblioteca viva}

O conceito de espectador avisado (espectateur averti) é proposto por Banu em sua obra Nosso Teatro, O Cerejal. Em seu Caderno de Anotações do Espectador (1999) deseja seguir o percurso de fidelidade à última obra de Tchekhov (1904). De 1968 a 1999, o espectador assiste a dezenove encenações da peça, o que o

\footnotetext{
1 Georges Banu nascido em 1943, na Romênia, é professor em Paris III - la Sorbonne Nouvelle. Dirige, com Bernard Debroux, a revista Alternatives théâtrales. Publicou obras sobre encenadores contemporâneos - Ariane Mnouchkine, Giorgio Strehler, Peter Brook, Peter Stein, Antoine Vitez entre outros e sobre atores.

2 Georges Didi-Huberman, nascido na França em 1951, é filósofo, historiador, crítico de arte e professor da École de Hautes Études em Sciences Sociales, em Paris.
} 
leva a salas em Paris, a teatros de cidades européias e norte-americanas, a apresentações no Festival de Avignon. Banu, no entanto, não perde de vista a montagem original do Jardim das Cerejeiras, no Teatro de Arte de Moscou, em 1904, com direção de Stanislavski.

O diário do espectador avisado circula em território familiar e organiza-se a partir de um tema e suas variações, indiferente às fronteiras entre texto e encenação. A lógica a seguir não é a de um exegeta, aproximando-se muito mais daquela praticada ao se escrever um diário de viagem, "nem sistemático, nem didático" (Banu, 1999, p. 11). Mas Banu adverte que não pretende, tal como é particular ao diário, constituir o arquivo de uma biografia. O caderno salva aquilo de que se lembra, o que está posto à disposição pela memória viva. Esta é a memória do espectador, "que retém principalmente a surpresa da primeira abordagem ou a evidência de um detalhe, o retorno de uma réplica ou o clareamento de uma zona de sombra" (Banu, 1999, p. 12). Enfatiza-se, ao final, uma prerrogativa do caderno do espectador, onde se excluem as decepções e se registram as memórias de momentos de confiança em que a cena procura e encontra, "em uma metáfora ou em um discurso inédito, o complexo do pomar" (Banu, 1999, 13), numa intrincada ligação entre planos, econômico e simbólico, onde se localiza uma dupla operação de salvação, ilusória e fracassada: salvar economicamente os donos de uma propriedade, sem sacrificar aquilo que simbolicamente justifica sua existência: o cerejal. Diante do texto que, como todo "complexo", ao mesmo tempo esclarece e escamoteia uma situação, o caderno caminha não no sentido do deciframento sistemático e rigoroso do que se mostra e do que está encoberto, mas no que se deixa perceber a partir do conceito de punctum, segundo Roland Barthes (Banu, 1999, p. 12).

O que comanda a escrita é um cruzamento intenso entre a ficção da obra, suas encenações e o que ressurge da vida do espectador. O cerejal estampa-se também na paisagem da Romênia, onde o complexo do pomar expressa a experiência vivida por sua mãe, espoliada de sua propriedade pelo exército russo durante a ocupação. Na perspectiva de reaver o bem, partem ambos em viagem à terra natal. Mas já não é mais possível reconhecer os lugares onde a mãe vivera. Sintetiza Banu: "Seu pomar em abismo só lhe pertencia agora fantasmaticamente. Visto pela última vez, (...) ele desaparece" (Banu, 1999, p. 17). 
Outra visada memorialística aparece ao analisar o tema da velocidade ou da "mudança de ritmo, em que a história se acelera, os desejos se precipitam, os vitoriosos não têm tempo a perder" (Banu, 1999: 24). A frase "Esta crueldade é insuportável" coloca em primeiro plano a personagem Lophakhine, mas a cena é mais uma vez da memória familiar. Um homem de negócios paga o preço alto de um quadro da coleção do pai, outro dos pomares que the atravessaram a vida. 0 autor do diário reconhece-se no personagem Pétia, que condena a celeridade de Lopakhine ao querer avaliar com rapidez o valor do cerejal. A frase final do fragmento diz respeito ao espectador e aos personagens de Tchekhov: "Vender é capitular, é fracassar, mas então que seja tudo feito sem a precipitação insuportável, confrontando-se com a lei dos novos donos" (Banu, 1999, p. 24).

Ao perseguir a hipótese segundo a qual é possível perceber no texto a exigência de "um equilíbrio entre abertura parabólica e enraizamento realista" (Banu, 1999, p. 18), tem início o cotejo de encenações para que se perceba de que modo se atribuem diferentes coloridos ao espírito do tempo. Segundo Banu, $O$ Cerejal é "uma obra reveladora, que faz aparecerem como na Química, um certo número de mutações que atravessam o século" (Banu, 1999, p. 18). Uma das entradas possíveis para esta vertente comparatista do teórico viajante são as personagens: Pétia, o estudante, ao longo de várias encenações, adquire tons diferentes, que vão do militante leninista histérico de Andreï Serban, ao visionário que antevê o fracasso antes de partir para a batalha, deixando aos espectadores a ilusão do século (Banu, 1999, p. 18).

Mas as dimensões do tempo proliferam, além do embate com a história. Recolhendo-se à sua rotina de erudito, Banu se percebe visitante de um cerejal ao entrar em bibliotecas antigas e lá se deparar com uma beleza anacrônica, "que se torna então refúgio passageiro, suspensão das leis do mercado e diminuição da velocidade" (Banu, 1999, p. 22). Teatro e livros se nomeiam mais uma vez como formas de resistência à rapidez e à eficácia, estados do tempo que se instalam para banir cruelmente a nostalgia.

As múltiplas facetas do tempo na peça poderiam, ainda, ser observadas a partir de uma cena - a chegada de Liuba. Banu reporta em breves parágrafos as diferentes soluções propostas pelos encenadores para responder à pergunta: como satisfazer uma espera e confirmar um acontecimento? Colecionam-se imagens: na montagem de Strehler, Liuba entra em cena com a postura de uma 
grande atriz que penetra na casa inteiramente branca. Já Stein prefere fazer Liuba avançar como em um sonho - êxtase de reencontros, enquanto dois outros diretores preferem apresentar a personagem como uma mulher arruinada pela idade, pelo álcool e pelo tabaco (Banu, 1999, p. 50). Da chegada, desliza-se para um tema oposto: a partida precipitada e o exílio de Liuba. As imagens do corpo das atrizes no palco são substituídas pela livre meditação sobre a fuga como incapacidade de se resignar a uma determinação distante do destino, a encontrar respostas no presente e a resolver as inquietudes persistentes. Há no exílio uma revolta tanto como um delito de fuga. Ao retornar à personagem em cena, Banu a percebe como uma comediante que dissimula uma derrota. Os contrastes ou as ambigüidade são esvaziados, como em encenações de Brook, Strehler e Efros, que só expõem o brilho sedutor da mulher, ocultando a testemunha do fracasso. Apenas uma atriz, em encenação de Zadek, apresenta o esplendor como uma ilusão.

A mais ampla visada comparatista das encenações parte da pergunta "É preciso representar o cerejal?", que se desdobra em outra indagação: É preciso ou não representar os fantasmas? Deve-se dar-Ihes carne, dar visibilidade ao invisível? Segundo Banu, as soluções propostas pelos encenadores "não são somente pessoais, porque carregam marcas de combates estéticos, de negações e de afirmações de uma época" (Banu, 1999, p. 28). Para compor respostas a estas perguntas, Banu organiza já nesta primeira parte de seu caderno uma espécie de galeria de imagens de cena. As anotações indicam um treinamento ou uma habilidade específica do espectador que deve proceder como se dispusesse de um olho-câmera, a captar fragmentos de cenas, recolhê-las em um arquivo ou uma coleção, para a seguir escolher algumas e criar séries.

Se na montagem original, no Teatro de Arte de Moscou, aparecem as árvores de cerejas pelas vidraças das janelas, e Stanislaviski integra discretamente nas paredes da casa flores e frágeis troncos, o cerejal é experiência subjetiva e a casa inteira, divisórias e seres vivos, participam do complexo do pomar. Uma crispação antinaturalista, no entanto, torna o cerejal simplesmente mental, mostra-se seu eco e não sua presença, como na montagem de Pintilié, em que se alternavam o branco e o bordô, produzindo o efeito cromático de um cerejal presente/ausente. Strehler converteu o cerejal num véu/cortinado de folhas mortas que envolvia a sala e a cena, produzindo uma câmara de eco que registrava e comunicava ao público o estado dos personagens febris. A 
transparência e a leveza tornam-se recusa obstinada da representação do pomar. Na encenação de Lassale em teatro de Oslo, projetam-se sobre o quarto das crianças imagens oníricas de um pomar sublime. O que seria uma performance tecnológica surpreendente em outros tempos, recebe do espectador Banu uma crítica aguda. Perde-se a matéria indispensável aos fantasmas tanto quanto aos pomares, abatidos a golpes de machado. Redimensiona as montagens de Brook, que as aboliu inteiramente para que brilhem livremente, e Zadek, que só as mostra mediocremente para provar a incapacidade da cena em reproduzir este lugar investido por fantasmas, pomar imaginário, pomar enganador (Banu, 1999, p. 30). Outras concretizações metonímicas do pomar, como de William, em Tóquio, - uma só árvore como o pilar do mundo contrastam com o sentimento do espectador avisado, perseguido pelo sentimento de ausência.

Mais uma vez é o discurso do viajante que fala mais alto. Lembra-se de ter sido testemunha, ao lado de alguém querido, do momento, em que as cerejeiras florescem no Japão. O comentário faz convergir experiências: "é preciso ver milhares de cerejeiras floridas para comprovar, como espectador, a sedução que elas exercem no outro lado, no lado dos personagens" (Banu, 1999, p. 31).

A despeito da memória irrepresentável, reconhece, no entanto, haver numa encenação de Peter Stein o compartilhamento deste encantamento ao mostrar o cerejal. Atrás da cortina, aberta por Varia, surge o cerejal "em todo seu envolvente esplendor... sensual e grandioso" (Banu, 1999, p. 31). Discutindo a questão da literalidade extremada, o teórico rejeita qualquer hipótese de naturalismo na opção steineana, porque o que brilha é a suprema experiência fantasmática. Após a sequência de breves análises, formula-se a pergunta nuclear do Caderno: representar ou não o cerejal só admite uma resposta: "De forma nenhuma" ou "Inteiramente". Segundo Banu, qualquer solução mediana decepciona porque transigiria com o supremo desafio: o desafio do invisível alcançado pelo visível (Banu, 1999, p. 32) plenamente realizado em dois espetáculos históricos na encenação branca de Giorgio Strehler e na policromia dos tapetes de Peter Brook.

Pensar ao lembrar e instabilizar opiniões são prerrogativas do caderno, prerrogativas da viagem no tempo e no espaço. Diferente do crítico em sua premência de emitir juízo, o espectador avisado pode vagar e alargar o tempo, 
oferecer ao leitor o seu pensamento em processo. É o que se percebe com bastante nitidez numa bela sequência em que Banu faz um corte temático em sua biblioteca viva para abordar o tema da morte na obra de Tchekov. (Banu, 1999, p. 33). O pesquisador parte da rememoração de espetáculo de Otomar Krejca, nos anos setenta: no segundo ato, um tecido branco cai sobre os pequenos móveis que desenham os vários ambientes; com este expediente cenográfico, os volumes se tornam semelhantes a pedras tumulares, fazendo com que a casa se converta numa necrópole em potencial. Na imagem criada na cena, mantém-se o lustre aceso que passa a indicar a recusa não só de separar o dentro e fora, mas também a morte e a vida (Banu, 1999, p. 36). Ao contrário da ambigüidade do primeiro espetáculo, em outra encenação a morte se impõe com mais agressividade, o cemitério ocupa o coração do palco e móveis e pedras tumulares coabitam com os vivos. A proposta de Efros quer atingir a resistência de uma estética realista, que na Rússia dos anos setenta, acabara de se aviltar. Sua estética petrificante pretendia liberar a obra tchekhoviana deste investimento através de um forte simbolismo. Diferentemente, Zadek respeita a didascália do segundo ato, mas sem conferir a ela nenhuma importância cenográfica em particular. É a imagem do personagem Firs na proximidade das pedras tumulares que se torna o emblema da morte que o espreita e o domina.

O espectador interessado permite-se atravessar para a relação entre as imagens produzidas pelos encenadores e uma imagem captada em carta de Tchekov, que afirmava, a propósito do início do segundo ato que as pedras lá estariam para receber as cerejas esmagadas como gotas de sangue (Banu, 1999, p. 37). É que Tchekhov escreve a peça já acometido de tuberculose. Portanto a morte é uma experiência pessoal que se confunde mesmo com a escrita. Finitudes partilhadas. Terminar a peça e aguardar o término da vida ou da comédia da vida.

O pesquisador-colecionador une o fragmento da carta de Tchekov, a fotografia de uma casa de Bucareste, presenteada por um amigo, em que predomina a beleza arruinada da antiga da edificação, incluindo, ainda, na série, a encenação de Zadek, que desenha o estado de deterioração da casa com restos de material emprestado de cenários teatrais antigos, portas diferentes, cadeiras disparatadas, louças descombinadas. As imagens das propriedades reais e as imagens reconstituídas em cena ecoam e tornam-se igualadas em sua condição de resíduos da memória. 
As miniaturas críticas e biográficas de Georges Banu sobre $O$ Cerejal contaminaram, desde a primeira leitura, a minha escrita da espectadora, diante do corpus de pesquisa com que me defrontei nos últimos anos - espetáculos cujas dramaturgias se baseiam em textos literários narrativos, de encenadores de Portugal e do Brasil. O movimento de compor uma bibliografia viva tem início, em junho de 2002, ao assistir, numa noite, em Palmela, nas proximidades de Lisboa, o espetáculo Alma Grande, encenado pelo grupo O Bando, a partir de um dos Contos da Montanha, de Miguel Torga. A percepção do viajante indicava que era importante a geografia, a paisagem, que se delineia ao cruzar o Tejo, percurso de travessia a ser repetido por anos seguidos. A memória da espectadora passa, então, a conviver com o afastamento necessário à operação analítica do objeto:

Há três anos antes, um trabalho do Grupo me levara a percorrer um longo e belo caminho em direção ao Vale de Barris, em Palmela. Recebidos por membros do grupo, fomos conduzidos a um platô atrás da construção que funciona como sede da Companhia, para, sentados em cem cadeiras reclináveis de lona branca, como as disponíveis nos convés de navios, assistir ao espetáculo Alma Grande, baseado em texto de Miguel Torga (Novos Contos da Montanha), que conta o inesperado embate de um abafador com Abel, que lhe corta o ímpeto sem hesitação de fazer a morte, e Isaac, o sobrevivente das mãos do abafador, que lhe põe termo nos dias. Numa estrutura semi-esférica projetada verticalmente, passeia de bicicleta o personagem principal; presas na passarela de ferro, reconhecem-se, janela, porta, cadeiras, uma plataforma - como o estrado de uma cama virada para cima - base sobre a qual se desenrolavam as cenas representadas por atores, que se movimentam no espaço, seguros por cordas e roldanas. O Destelhado, "uma rua onde ainda mora o vento galego, a assobiar sem descanso o ano inteiro" fazia-se em imagem que preservava a referência ao percurso de ir e vir pela encosta acima e abaixo, não só dos que se socorrem dos préstimos o Tio Alma Grande, quanto do próprio personagem quando parte em direção à casa do moribundo cuja família Ihe deseja abreviar o sofrimento.

O maquinismo, a música - canto e instrumental de Jorge Salgueiro executada ao vivo, produzia o efeito onírico pretendido pelo encenador João Brites, que já no programa de peça nos apontava o universo de Marc Chagal como referência visual para o espetáculo. Recostados e protegidos com cobertores do vento de primavera que vem do vale do Rio Sado, rodeando a encosta do Castelo de Palmela, éramos sequestrados para um espaço singular e arrebatador. Os limites deste espaço teatral eram estabelecidos pela máquina de cena que, sobre o fundo escuro de um céu com poucas estrelas, suportava os atores e funcionava à vista dos espectadores. Um objeto-máquina, cujo uso só muito de longe remete à tradição dos maquinismos, escondidos nos porões e no urdimento dos teatros antigos. Anti-ilusionista, a máquina de cena converte-se em construção de um espaço imaginário forte. Somos, nós os espectadores, tragados para o sonho. Saímos do chão de terra do Vale de Barris para um espaço de contornos imprecisos onde 
flutuam corpos e sentimentos, ora submetidos ora libertos do negror da morte (Werneck, 2005, p. 290).

A percepção acerca das múltiplas variações que a relação entre dramaturgia e espaço recebe do grupo é resultado de uma prática investigativa que trafega das páginas impressas, sejam obras que servem de ponto de partida para o texto de trabalho, sejam obras que fornecem referências conceituais. No entanto, o esforço de descrever as encenações não prescinde do rumor da memória, que se constitui em camadas, infiltradas de imagens reiteradas. A espectadora avisada vai construindo, assim, uma série que tem a ver com a inserção física nos espaços em que os espetáculos se instalam e neles criam receptáculos. Nestas novas paisagens, o escuro da noite, o manuseio dos elementos Terra, Fogo, Ar e Água, além das plataformas erguidas à distância do chão criam modos paradoxais de errância e de acolhimento, estabelecendo novos laços entre atores e espectadores, ambos tomados pela experiência de deslocamento e pela vivência da desestabilização de papéis preconcebidos (Werneck, 2009, p. 11).

A tarefa analítica vai ao encontro de imagens; procuram-se correspondências e desacordos, similitudes e dessemelhanças que se depositam numa estética em movimentos de mutação e de retorno. O tempo se mostra em múltiplas temporalidades, dispersando a cronologia rigorosa da série histórica, uma das liberdades que o Caderno de Banu propõe como prática de pesquisa. O meu caderno de anotações registra mais três espetáculos do grupo - Cabeça de prego sem cabeça (2007), Saga, ópera extravagante (2008) e Rua de dentro (2010). Em todos os espetáculos, a noite, já constituída como imagem, decantada pela memória, tornava-se a entrada para um tempo fadado a escapar, que imediatamente iniciado o espetáculo, perde a sua dimensão cosmológica e adquire outra, material, teatral, apontando para a duração, uma temporalidade na qual a imaginação transborda limites. No limiar do espaço real e do espaço ficcional, a imagem da noite indicava a suspensão de um tempo e início de outro, base de uma teatralidade que se sobrecarrega de recursos - máquina de cena, figurino, em que se cruzam inúmeras fontes de referência, investimento máximo na pesquisa da oralidade e da corporalidade (Werneck, 2012, p. 231).

\section{Constelação de imagens}

A forma do diário é invocada pelo autor do segundo trabalho, que nos faz pensar sobre a pesquisa em artes. Em nota bibliográfica ao final do livro Le Danseur des 
solitudes, Didi Huberman informa que se trata de parte de um trabalho em curso, mais extenso sobre a arte do cante jondo (hondo), o canto profundo da música flamenca, e a escrita diarística resulta dos encontros com o dançarino Israel Galván entre 2004 e 2005, três em Sevilha (num festival, em um seminário e no estúdio do dançarino) e dois na França, em Marseilles e Arles. Mas há uma outra cronologia nesta escrita; ela está posta na datação dos capítulos (10/08/05; 23/08/2005; 31/08/2005; 10/10/2005), ${ }^{3}$ produzidos, portanto, durante exatamente um mês, na sequência do últimos encontro com Galván, filmado por Pascal Convert, artista plástico e documentarista. ${ }^{4}$

São quatro os capítulos, estruturados de tal forma que a proximidade com o bailaor sevilhano se intensifica, mas ao mesmo tempo exige o afastamento em direção a títulos de uma biblioteca organizada nos moldes warburguianos, em busca de novos e ampliados vínculos entre a dança e sua boa vizinhaça, "visando despertar no leitor perspectivas, cumplicidades, convivências, correspondências cada vez mais ricas" (Samain, 2012, p. 35). Didi Huberman parte do espetáculo Arena, a que assistiu no Teatro de La Maestranza, programação da Bienal de Dança, e a ele retorna inúmeras vezes, ampliando a cada retomada a compreensão do solo de dança.

A proposição inicial é colocar em suspensão a ideia de que se dança apenas para se estar em conjunto e verificar a maneira através da qual os homens dançam seus símbolos, afetos e crenças para transmitir, na longa duração, nas formas culturais de seus movimentos psíquicos e corporais. Ao considerar a arte segundo os gestos humanos, no entanto, esta abordagem acaba por separar a dança de outras artes como a arquitetura, a escultura, a pintura. E, positivamente, o ensaio caminha para transpor o isolamento das artes, pensando com Nietzsche, que vê nas danças populares ou trágicas a possibilidade exemplar de ver surgir "imagens vivas" (Didi-Huberman, 2006, p. 13).

O encontro com Israel Galvan é narrado por Didi-Huberman um ano depois de vê-lo em Sevilha:

\footnotetext{
3 Blanchot indica que, no diário íntimo, o calendário é o seu demônio, o inspirador, o compositor e o vigilante. Ao escrever um diário nos colocamos momentaneamente sob a proteção dos dias comuns, colocara escrita sob esta proteção e, também, proteger-se da escrita, submetendo-a "regularidade feliz que nos comprometemos a não ameaçar" (Blanchot, 2005: 270). A biblioteca, o atlas no sentido wargburiano utilizado por Didi-Huberman, dispensa a proteção do calendário.

4 Em seu site se apresenta como "arqueólogo da arquitetura, da infância, da história, do corpo" (http://www.pascalconvert.fr/).
} 
Ele dançava, só. Não que ele avançasse na frente de outros menos virtuosos que ele para fazer um solo, não. Não que ele simplesmente evoluísse sem parceiros de dança. Ele parecia, ao contrário, dançar com sua solidão, como se ela fosse, fundamentalmente, uma solidão parceira, isto é, uma solidão complexa, povoada de sonhos, de fantasmas, de memória. E, assim, ele dançava suas solitudes, criando dessa forma uma multiplicidade de um gênero novo (Didi-Huberman, 2006, p. 15).

A dança flamenca chega ao público principalmente como balé espanhol, integrando ao nome das estrelas um conjunto de bailados. Mas Israel Galvan volta, ao "dançar só acompanhado", ao centro do que constitui fundamentalmente a arte do "baile flamenco". Trata-se de um bailaor, um artista do baile jondo (rondo), do dançar profundo (Didi-Huberman, 2006, p. 16).

Para expor o que são as solidões espaciais, a hipótese é de que "o dançarino se isola para ser vários, não constrói um para si mesmo nem unidade, nem conjunto, mas constrói o múltiplo com seu próprio corpo em movimento - uma singular multiplicidade, é o que se poderia dizer" (Didi-Huberman, 2006, p. 17). O encantamento do historiador se completa quando descobre que o dançarino Ihe oferece uma questão filosófica e tanto.

As descrições das coreografias de Galván constituem belas páginas de escrita em que se percebe total atenção com esta singular multiplicidade, como a distinção entre reserva e brilho, entre mostrar e aparecer, conceitos que indicam como ele cria as condições para dizer tudo de sua própria ausência. Segundo DidiHubermam, Galván escapa da colagem cultural de referências da dança moderna, que utilizaria um pouco de Pina Baush e de Merce Cunningham. Sua potência vem de um pensamento interno à dança, ligada por tradição à tauromaquia. Mas a ela impõe extensão figural e beleza inéditas (DidiHuberman, 2006, p. 43).

No texto "Arena ou As solidões espaciais", trata-se de registrar as escolhas formais, através das quais se revelam os modos de ser do artista, onde estão sedimentadas a modéstia e o laconismo do discurso, que merecem do estudioso a síntese: "ele gostaria saber aparecer sem se ver como tal"; "ele jamais anuncia que vai se tornar sublime"; "seu corpo produz fórmulas em que o pathos permanece, diante de nós, mas em suspensão, como flutuando na sombra" (Didi-Huberman, 2006, p. 22). Aos poucos se inicia a espiral hermenêutica que chama Valéry à escrita e que conduz a Beckett, de Quad, por onde se chega, finalmente, ao espetáculo Arena, cuja dramaturgia é orientada pela poética e 
pela estética das obras José Bergamin, escritor e poeta espanhol, consagradas à tauromaquia. Entre a tourada e a dança, Israel Galván procura alguma coisa que está à igual distância da ferida e da beleza (Didi-Huberman, 2006, p. 38).

Ao se deparar com uma sequência de movimentos de desvio ou mudança de direção, de esquivas de contato, de afastamento da graça habitual do corpo que se sabe dançando, o gesto crítico dirige-se, então, para a comparação entre a nova estética do bailaor sevilhano no baile flamenco e a estética que Juan Belmonte impôs à arte de tourear. Ambos, antes de tudo relacionam-se com a noite, com a sombra, com a obscuridade (Didi-Huberman, 2006, p. 46), desenhando a seguir temas paralelos referentes ao vazio necessário para que ele se escute produzir os passos. Uma pergunta feita a Galván sobre a penumbra produz numa resposta determinante: enquanto dança, "o ar é simplesmente sua carne" (Didi-Huberman, 2006, p. 48). O confronto entre a afirmação e a descrição do espectador permite a construção da hipótese segundo a qual o aire (palavra espanhola para o ar intangível e sem limites) é um material psíquico do medo e da assunção do risco (Didi-Huberman, 2006, p. 48).

A passagem revela outro interesse para nossa leitura desconstrutora da pesquisa escrita e registrada no livro: Galván, que adota o caminho do não-saber: humildade, laconismo, inocência, estados que se revelaram em algumas entrevistas concedidas ao estudioso é, segundo seu espectador, um maravilhoso sábio de gestos inventados e recusados. Trata-se de estar diante, de uma obra contemporânea, resgatando seu "saber do inconsciente" segundo a rítmica do compás flamenco e da musicalidade silenciosa das suertes tauromáticas (DidiHuberman, 2006, p. 50). Há em sua dança um sonambulismo, mas que não tem nada a ver o estado da possessão pelos deuses nem com o da histeria romântica.

Galván se apresenta, então, para Didi-Huberman como um dançarino anacrônico, que reconfigura a profundidade imemorial de sua arte com olhar sobre o cinema, de Eisenstein à Matrix ou mesmo filmes de artes marciais tailandesas (Didi-Huberman, 2006, p. 50). Mas em seu corpo estão ainda as memórias de outros toureiros sempre poetizadas por Bergamin, autor que permite a Didi-Huberman associações com Garcia Lorca, Alberti e Michel Leiris, San Juan de La Cruz, Bataille. A biblioteca warburguiana não cessa de produzir a ampliação das fronteiras temáticas e geográficas da história da arte (Agamben, 2009, p. 17). 
Ao mesmo tempo em que se ampliam as referências, é preciso fechar a lente de observação. A arte de se multiplicar e de se subtrair está na dança tanto quanto no modo como o dançarino fala. O espectador interessado mostra sua proximidade com o corpo do dançarino e assume o discurso do testemunho:

Ver Galván dançar é descobrir, na escala de um corpo, o conflito entre a fluidez e a acentuação. É ver alguém que forjou - a que preço? Nós não saberemos (...) - uma grande arte da disjunção. Temos a impressão que Galván se impõe a lógica perigosa do toureiro - enfrentamento, afastamento, corte - no interior de seu próprio corpo, de seus próprios gestos. Ele está só com seus conflitos. Ele está separado por seus conflitos. Só, ele é, no entanto, múltiplo (Didi-Huberman, 2006, p. 86).

A análise caminha para os modos de desmontagem de movimentos e gestos que, no conjunto, impõem tanto o sublime e a "dignidade do medo" quanto o grotesco do medo, quando ele se torna pânico (Didi-Huberman, 2006, p. 89). DidiHuberman vai novamente em busca de novas imagens e a memória convoca grandes artistas burlescos (Harold Lloyd, Charles Chaplin ou Buster Keaton), numa galeria na qual se integram também as lembranças de Galván sobre espetáculos de flamenco burlesco que o marcaram. A passagem pela distinção entre os conceitos de cômico e gracioso leva não só aos escritos de Bergson, mas também, evidentemente, ao cinema, aos escritos de André Bazin, onde se encontra nova perspectiva para a ideia de "Rematar", agora como matar em repetição, de intensidade da parada repetida (Didi-Huberman, 2006, p. 97).

Vários toureiros povoam as páginas do estudo, em que o espectador de Galván já se permite criticar a visão do poeta Bergamin, quando este prefere o estilo de Joselito, linha curva e rapidez, ao de Belmonte, a predominância da lentidão. Da crítica ao poeta, o pesquisador salta para a formulação de uma surpreendente hipótese sobre o dinamismo imóvel de Juan Belmonte: saber ser estátua e homem em frente ao touro só poderia ser perceptível se impusesse ao público uma nova técnica de observação, com a qual apenas a invenção do cinema poderá contribuir (Didi-Huberman, 2006, p. 111).

Galván, para Didi-Huberman, recupera este dinamismo imóvel forjado por Belmonte na arena, e que o cinema mostra como dispositivo de fragmentação do tempo - os fotogramas são paradas, mas o desenvolvimento do filme faz, diante de nossos olhos, dançar todas as coisas, mesmo aquilo que parecia de início imóvel (Didi-Huberman, 2006, p. 113). Trata-se, portanto, de afirmar que "Galván só para de dançar por fragmentação do tempo, parada sobre a imagem 
e trabalho de montagem, quando se produz o instante privilegiado, acontecimento: um tipo de salto onde se fundem profundidade e humor. A grande arte do remate, esta maneira de "finalizar em beleza" torna Galván um contemporâneo de vários campos e vários tempos heterogêneos, entre sobrevivências imemoriais e antecipação de nossas expectativas mais contemporâneas. O estudioso retoma o conceito, o dançarino é anacrônico, deslocado com graça no mundo de hoje (Didi-Huberman, 2006, p. 126).

A última entrada do diário, "Temples ou solidões temporais", trata da grande arte do ritmo. Toureiro (Belmonte) e dançarino (Galván) são postos novamente em comparação na fórmula de paradoxos; paradoxo de tempo - a lentidão fugaz; paradoxos do movimento; paradoxos de consistência, paradoxos de forças. Dançar é se pôr em combate com a música, sendo simultaneamente homem e animal, um corpo de fauno. Didi-Huberman não se contém, prerrogativa da sinceridade do diário, e confirma uma impressão nietzscheiana - trata-se de um deus que dança (Didi-Huberman, 2006, p. 161).

O convite à confirmação da frase é feito: basta olhar as mãos. Depois de impressionante sequência, em que descreve os inúmeros movimentos das mãos do bailaor, admite, em comparação com os golpes de punho de um guitarrista, que corta (rematar) ou adoça (templar): Galván sabe capturar o tempo com as mãos (p. 162). O último texto do diário se conclui com uma espécie de agradecimento interrogativo: Como é possível se surpreender hoje? Diante da coreografia tão profundamente tauromática de Arena, diante estes gestos tão cortados, no entanto tão suaves, que Galván nos faça experimentar um "sabor do tempo", onde se reconhece alguma coisa como um nascimento contemporâneo da tragédia?

O modelo wargburiano de análise desenvolvido por Didi-Huberman apresenta-se como um horizonte de conjunção de referências. Tanto no estudo sobre a dança de Galván quanto em seus sucessivos textos sobre instalações de James Turrel, reunidos em L'Homme qui marche dans la couleur, exalta-se a mobilidade crítica, muito além da extremada visada semiológica que remete para a exigência compósita de descrever e interpretar, desmontar e criar simulacros dos objetos.

Tomar um livro de Didi-Huberman nas mãos no início de um trabalho é deixar-se levar pelas associações que um conceito pode produzir, pela memória de leituras, pela possibilidade de instalar-se numa disjunção que romperia com o 
paradigma representacional da arte, tal como formulada por Ranciére "suspensão de toda e qualquer relação determinável entre a intenção de um artista, uma forma sensível num lugar dedicado à arte, o olhar de um espectador e um estado de comunidade" (Ranciére, 2010, p. 86). O pesquisador pode se deixar conduzir por múltiplos regimes de sensorialidade e criar seus próprios projetos de arqueologia de um espetáculo, aproximando-se da elaboração de uma ficção crítica.

Assim, nos limites entre a ficção e a crítica, poderia definir a escrita de um breve texto sobre a encenação de Cartas portuguesas, em 1991, e Viagem ao centro da Terra, de Julio Verne, por Bia Lessa, em 1993, elaborado por mim. Embora o acervo de espetáculos de Bia Lessa construídos a partir de textos literários, entre as décadas de oitenta e noventa, seja significativo, a decisão de privilegiar dois entre os experimentos da encenadora procurava alargar o conceito de desertificação, proposto por Jean Pierre Sarrazac para enunciar um dos componentes da estética de encenação teatral nos finais do século XX. Nas várias operações de reversibilidade do espaço cênico projetadas pela encenadora nos teatros do Centro Cultural do Banco do Brasil, no Rio de Janeiro, indicava-se a propriedade do conceito, que deveria ser estendido à sua origem geográfica e às suas manipulações na modalidade de instalação site specific, como nos trabalhos de James Turrel. O ir e vir em torno do conceito e seus arredores, onde também se instalam os textos literários, cria as vizinhanças produtivas que fortalecem e, ao mesmo tempo, tornam surpreendente o gesto crítico do espectador avisado. 


\section{Referências Bibliográficas}

AGAMBEN, Giorgio. Aby Warburg e a ciência sem nome. Revista Arte \& Ensaio, Revista do Programa de Pós-Graduação em Artes Visuais, EBA/UFRJ, Rio de Janeiro, ano XVII, n. 19, p. 131-141, 2009.

BLANCHOT, Maurice. O Diário Íntimo e Narrativa In: O livro por vir, Trad. Leyla Perrone Moisés. S. Paulo: Martins Fontes, 2005.

BANU, Georges. Notre Théâtre. La Cerisaie, cahier de espectateur. Arles: Acts SUDS, 1999.

DIDI-HUBERMAN, Georges. Le Danseur des solitudes. Paris: Les Éditions Minuit, 2006.

DIDI-HUBERMAN, Georges. L' Homme qui marche dans la couleur. Paris: Les Éditions de Minuit, 2001.

DIDI-HUBERMAN, Georges. Texto de apresentação da Exposição Atlas Cómo Llevar El Mundo A Cuestas?, 26 de Novembro de 2010 - 28 de Março 2011, Museo Nacional Centro de Arte Reina Sofia, Madrid.

RANCIÉRE, Jacques. O espectador emancipado. In: $O$ espectador emancipado. Trad. José Miranda Justo. Lisboa: Orfeu Negro, 2010.

SAMAIN, Etienne. As "Mnemosyne(s)" de Aby Warburg: Entre Antropologia, Imagens e Arte. Revista Poiesis, Niterói, v. 17, Ano 12, p. 29-52, julho 2012.

WERNECK, Maria Helena. Operações radicais de dramaturgia; rastros de imagens cênicas no teatro de Bia Lessa. Anais do VI Congresso ABRACE, 2010. Disponível em: http://portalabrace.org/vicongresso/teatrobrasileiro/MariaHelenaWerneck.pdf Acesso em: 27 mar. 2013

WERNECK, Maria Helena. Espaço teatral. A literatura e as imagens em cena. In: MARGATO, Izabel; GOMES, Renato Cordeiro (Org.). Espécies de espaço. Belo Horizonte: Editora UFMG, 2008.

WERNECK, Maria Helena. Memória e imagem - registro da cena narrativa em vídeo. In: FLORES, M. Bernadete Ramos; PETERLE, Patrícia (Org.). História e Arte. Imagem e Memória. Campinas: Mercado de Letras, 2012. 